\title{
Following Editor's Steps in Ophthalmology and Advance Research before the End of 2021
}

\author{
Sunny Chi Lik Au ${ }^{1 *}$ \\ ${ }^{1}$ Department of Ophthalmology, Pamela Youde Nethersole Eastern Hospital, Tung Wah Eastern Hospital, Hong \\ Kong \\ *Corresponding Author: Sunny Chi Lik Au, MBChB, MRCSEd, AFCOphthHK, Department of \\ Ophthalmology, Pamela Youde Nethersole Eastern Hospital, Tung Wah Eastern Hospital, Hong Kong; \\ Email: kilihcua@gmail.com
}

Received Date: 17-10-2021; Accepted Date: 08-11-2021; Published Date: 15-11-2021

Copyright $^{\odot} 2021$ by Au SCL. All rights reserved. This is an open access article distributed under the terms of the Creative Commons Attribution License, which permits unrestricted use, distribution and reproduction in any medium, provided the original author and source are credited.

\section{Introduction}

2021 has already been coming to the end when I am writing this in the $4^{\text {th }}$ quarter, and Christmas is on the way. With the COVID-19 pandemic continuously hoisted throughout 2021, most of the academic conferences were turned into virtual, or if possible, hybrid form to cater only for local delegates $[1,2]$. Air travel and border crossing are still not common despite the gradually increasing rate of vaccination worldwide. Here, to celebrate the success of our journal's second volume to expand up to her third issue, I am going to introduce a few virtual conferences in ophthalmology and advance researches before 2021 ends.

Famous international ophthalmology conferences like American Academy of Ophthalmology (AAO), World Ophthalmology Congress (WOC), Asia-Pacific Academy of Ophthalmology (APAO) congress are all well known to the readers [3-5]. Concerning our locality in the Asia pacific region, we could go through the official website of APAO's meeting calendar page. I would like to highlight two coming virtual conferences, the 14th Asia-Pacific Vitreo-retina Society (APVRS) Congress on December $11^{\text {th }}-12^{\text {th }}$ and $33^{\text {rd }}$ Annual Scientific Meeting Hong Kong Ophthalmological Symposium 2021 from $4^{\text {th }}$ to $5^{\text {th }}$ December 2021. 


\section{Keywords}

Ophthalmology; Retina; Macula; Surgery; Conference; Eye

\section{APVRS Congress}

Since the 2019 congress in Shanghai, the pandemic pulled 2020's meeting to a stop. Being the first-ever 2-day weekend virtual congress in the history of APVRS, it provides cutting-edge innovations and knowledge in the field of vitreoretina. With the theme of "Beyond All Limits", it provides a platform for academic exchange relevant to vitreoretinal diseases. Congress information and content is available in both iOS (Fig.1) and Android (Fig. 2). This year's interactive element is public abstract voting on either Free Paper, E-Poster, or Video. It will be held in October - November. Delegates can vote for their favourite abstracts, and Most Popular Awards will be given out.

One of the featured abstract is "Topographic and angiographic correlation with visual outcomes in hyperbaric oxygen treated central retinal artery occlusion eyes - the HORA study report". HORA study refers to the Hyperbaric Oxygen therapy for central Retinal Artery occlusion study, it is the territory wide study lead by Dr. Sunny Chi Lik Au and Dr. Callie Ka Li Ko in Hong Kong since 2018 [6,7]. It has published its $4^{\text {th }}$ report recently on the delayed hospital presentation of acute central retinal artery occlusion during the COVID-19 crisis [8]. Upon PubMed search, multiple publications mentioning HORA study were found across different specialties' journals $[9,10]$. It would be interesting to go through their published reports one by one. Going back to our journal, this HORA study working group also shared their work on the development of hyperbaric medicine in ophthalmology, mainly on treating central retinal artery occlusion in our last issue [11].

\section{Annual Scientific Meeting Hong Kong Ophthalmological Symposium}

After walking through the vitreoretinal aspect of the eye, we now come to the anterior segment on Dry Eyes and Ocular Surface Diseases. With a history of 33 years, this symposium is organizing her second virtual annual scientific meeting [12]. This year, two distinguished keynote speakers, Dr. Sayan Basu from India and Prof. Norihiko Yokoi from Japan, will share their world-renowned clinical expertise on Dry Eyes and Ocular Surface Diseases. The pandemic has profoundly changed our everyday lives. Home confinement, work-from-home and E-learning have all led to increased "screen time". The combination of reduced frequency and intensity of blinks during "screen time" in turn increases the risk of inducing or exacerbating dry eye diseases. This conference pair up with the timely concern on our eye health under the pandemic. Professor Norihiko Yokoi from Kyoto Prefectural University of Medicine will share his expertise on tear film dynamics and management of dry eyes, while

Au SCL | Volume 2; Issue 3 (2021) | JOAR-2(3)-025 | Editorial

Citation: Au SCL. Following Editor's Steps in Ophthalmology and Advance Research before the End of 2021. J Ophthalmol Adv Res. 2021;2(3):1-4.

DOI: http://dx.doi.org/10.46889/JOAR.2021.2306 
Professor Sayan Basu from LV Prasad Eye Institute will enlighten us on corneal stem cell therapy and showcase the management of complex ocular surface diseases.

Going through the program, other than the routine Resident Challenge and Young Ophthalmologist (YO) Symposium, there are also separate sections for Indian Ophthalmology Society and Japan Ophthalmology Society respectively [13]. Besides the prestigious Dr Timothy Kai Ching Liu Memorial Fund Awards for Outstanding Oral and Poster Presentations for pre-Academy fellows, abstracts of sufficient quality will also be published in the supplement issue of the Hong Kong Journal of Ophthalmology.

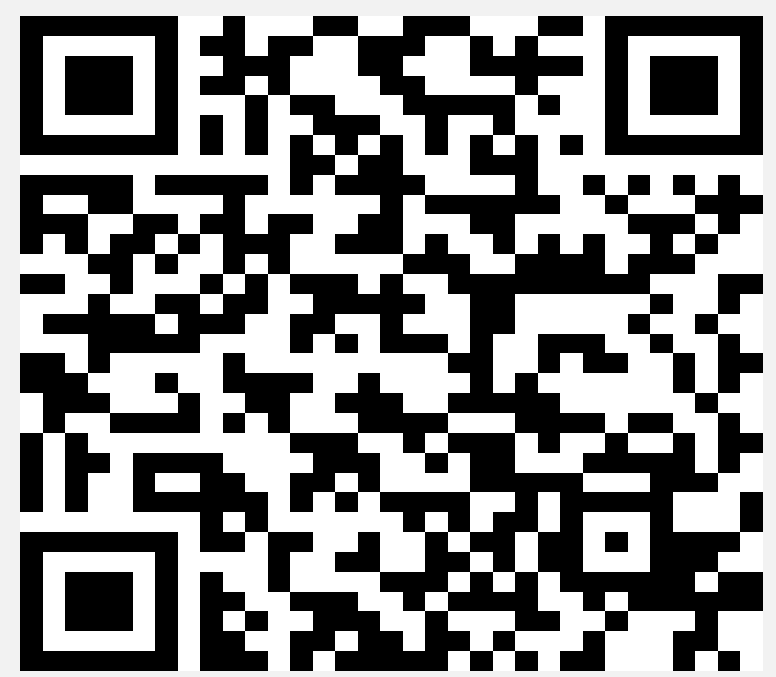

Figure 1: Congress apps on iOS.

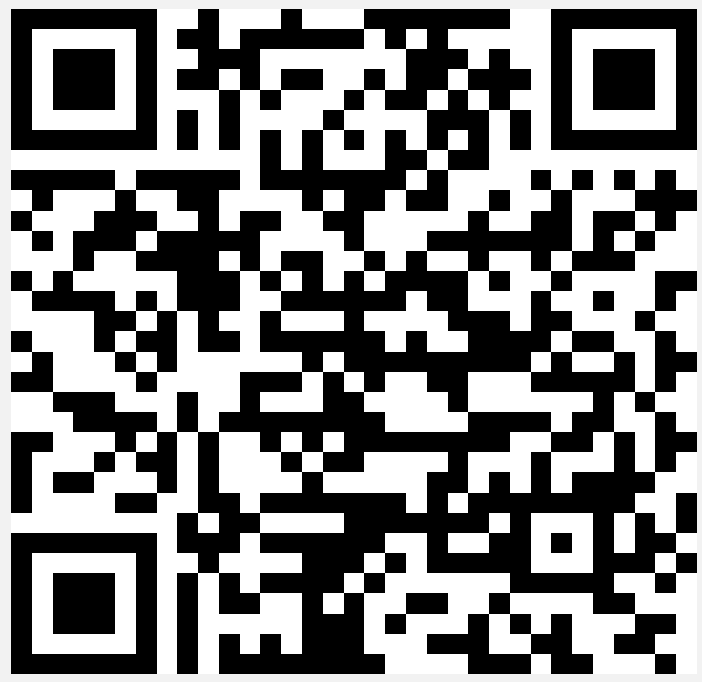

Figure 2: Congress apps on Android. 


\section{Conclusion}

The pandemic has prompted major shifts in how we attend ophthalmology congresses. The pandemic has impacted the ophthalmology conference arena, virtual meetings nowadays are retaining much of the inherent value associated with the in-person meetings.

\section{References}

1. Au SC. The transition of academic meetings in 2020. Cancer Res Stat Treat. 2021;4:117-8.

2. Gupta MP, Sridhar J, Wykoff CC, Yonekawa Y. Ophthalmology conferences in the coronavirus disease 2019 era. Curr Opin Ophthalmol. 2020;31(5):396-402.

3. Parke DW $2^{\text {nd }}$. COVID-19 Era Impacts on the American Academy of Ophthalmology. Ophthalmology. 2020;127(11):1447-50.

4. Date A, Nigam Ch. Highlights of advances in medical retina from the virtual world ophthalmology congress 2020. Cesk Slov Oftalmol. 2020;76(5):227-30.

5. Abstracts of the $20^{\text {th }}$ Asia Pacific Academy of Ophthalmology Congress, Kuala Lumpur, Malaysia, 27-31 March 2005. Am J Ophthalmol. 2005;139(4 Suppl):S1-71.

6. Au SCL, Ko CKL. Comments on coronavirus positive patients presenting with stroke-like symptoms. J Stroke Cerebrovasc Dis. 2021;30(7):105741.

7. Yip LT, Au SCL, Ko CKL. Hyperbaric oxygen therapy for central retinal artery occlusion: experience in Hong Kong. Hong Kong J Ophthalmol. 2020;24:44-50.

8. Au SCL, Ko CKL. Delayed hospital presentation of acute central retinal artery occlusion during the COVID19 crisis: the HORA study brief report No. 4. Indian J Ophthalmol. 2021;69(10):2904-5.

9. Au SCL. The hyperbaric oxygen therapy protocol in acute central retinal artery occlusion seen within 24 hours at a tertiary institution. J Stroke Cerebrovasc Dis. 2021;30(11):106044.

10. Au SCL. Central retinal artery occlusion in COVID-19. Indian J Ophthalmol. 2021;69(10):2905-6.

11. Au SCL, Ko CKL. The ophthalmology development of hyperbaric medicine for treating central retinal artery occlusion in Hong Kong. J Ophthalmol Adv Res. 2021;2(2):1-8.

12. Valenzuela F. The Hong Kong ophthalmological symposium 99. Br J Ophthalmol. 1999;83(12):1409H.

13. Yong WWD, Koh TCV, Shen L, Misra DK, Leung WYJ, Chandrasekaran S, et al. A survey of young ophthalmologists' perception of training in Asia during COVID-19. Ann Acad Med Singap. 2021;50(9):72932 . 